\title{
LETTERS
}

\section{Cannabis use, legalization and youth health}

In a recent editorial in CMAJ, Dr. Kelsall states that cannabis use harms the developing brain and brings other key health risks to youth (i.e., those aged less than 25 years), and thus "cannabis should not be used by young people." ${ }^{1}$ On this basis, according to the editorial, Bill C $-45,{ }^{2}$ the federal bill proposing legalization of nonmedical cannabis use and supply for people ages 18 or older (discretionary upon provincial regulations), should not go forward. Although we concur with the general assessment of cannabis use - related health risks to youth as a key vulnerable population - we categorically disagree as consistently advocated elsewhere ${ }^{3,4}-$ with the conclusion that legalization will work against the protection of the health of the public and especially youth. Why? Because the challenge of effectively protecting youth health as related to cannabis use is complex and involves several variables not considered by Kelsall, and it is indeed legalization with strict regulation that provides a unique opportunity to realistically address these.

The main points are:

1) Kelsall suggests that cannabis use may cause harms to the brain and development, and serious overall harm to the health of young people. These health risks of cannabis use are real, and are especially so for those characterized by intensive cannabis use that begins early in the teenage years and involves highpotency cannabis products. ${ }^{5-7}$ Based on this logic, however, we would also need to categorically prohibit both alcohol use and hockey to protect young people's health, because equally serious brain and other health harms occur from those activities in young people. ${ }^{8-11}$ Such measures are not currently being discussed in the interest of youth health.

2) Certainly, in theory, all cannabisrelated health risks would be best eliminated by abstention, and from a public health perspective, abstention among youth (or everyone in general) would be the "ideal" solution in terms of avoiding these health risks. This is, evidently, not anywhere realistic or feasible. For decades, existing prohibition law and policy has aimed to purge cannabis use from the Canadian population; however, a persistent one in three people in the 16-25 years of age group (trends are rising) are active users. ${ }^{12,13}$ Therefore, youth "not using cannabis" is a futile illusion in current reality, and Kelsall does not propose new or improved approaches to realistically change this.

3) Importantly, and a consequential effect of point two, the current dynamics of cannabis prohibition actively contribute to, and worsen, the health risks of cannabis use for youth. Why? For a few select reasons: It forces youth users to obtain cannabis from the black market (where it is likely at least as easily available and accessible as it would be in legal but regulated markets). The black market provides only unregulated - and privileges highpotency/high-risk over lower-risk cannabis products. Most users do not have reliable information about the characteristics and health risks of the cannabis products they are using. ${ }^{14-16}$ Moreover, youth obtaining cannabis from illicit markets expose themselves to criminal environments, in addition to the social consequences of becoming stigmatized "criminals," as many youth have been arrested and have criminal records for cannabis-related offenses. ${ }^{17,18}$ Thus, the tangible impacts of the status quo of enforced abstention are not protecting youth's health and well-being, and are not a realistic or desirable way forward.

4) There is opportunity to substantially - although surely not entirely reduce acute and long-term health risks related to cannabis use for youth by legalization, with strict public health-oriented regulations, specifically through certain key regulatory provisions and measures allowed for - partly still to be developed - under the bill. Regulations for cannabis product availability and dispensing in emerging legalized systems should include, among others: restrictions for high-risk cannabis products, clear product labelling, informed and behind-the-counter distribution, and strictly but sensibly regulated and restricted distribution. ${ }^{3,4,19}$ These measures shall help to take (most) youth consumers away from illicit markets and into legal distribution systems, while facilitating overall safer cannabis access and use among this vulnerable group. In addition, legalization will provide the distinct opportunity - whether in schools, universities, among peers or in general public discourse, for example, through evidencebased guidelines for lower-risk cannabis use or other strategies ${ }^{20}$ - for open and direct health-oriented education to consumers of cannabis in a legalized system.

We fully agree with the core spirit of the article by Kelsall that we have to get cannabis policy right for the public's, and especially for youth health, who because of both high use rates and distinct vulnerabilities - have the most at stake and ought to be the priority focus. ${ }^{4,21}$ However, to achieve this by a sudden elimination of cannabis use by youth through maintaining the status quo is both wishful and unrealistic thinking at best, and will continue to generate substantial collateral harms among youth as the worst outcome. Thus, we believe that carefully regulated legalization of cannabis use and supply through both its intended direct and indirect (e.g., dispersion) effects - promises to reduce substantially the severity of health risks related to cannabis use for youth. ${ }^{3}$ It is a goal that we, more realistically, believe is achieveable, rather than counting on a sudden reversal of the failed or negative outcomes of continued cannabis prohibition.

And this is why, we - in the explicit interest of public, and especially the health of youth - have consistently advocated for and supported cannabis legalization with strict regulation, and continue to do so.

\section{Benedikt Fischer PhD Jürgen Rehm PhD}

Institute for Mental Health Policy

Research, Centre for Addiction and Mental Health (CAMH); Department of Psychiatry, University of Toronto; Institute of Medical Science, University of Toronto, Toronto, Ont. 
Cite as: CMAJ 2017 July 24;189:E971-2. doi: $10.1503 / \mathrm{cmaj} .733215$

\section{References}

1. Kelsall D. Cannabis legislation fails to protect Canada's youth [editorial]. CMAJ 2017;189:E737-8.

2. Bill C-45. Cannabis Act - an Act respecting cannabis and to amend the Controlled Drugs and Substances Act, the Criminal Code, and other Acts. First reading 2017 Apr. 13, 42nd Parliament, 1st session.

3. Rehm J, Fischer B. Cannabis legalization with strict regulation, the overall superior policy option for public health. Clin Pharmacol Ther 2015;97:541-4.

4. Crépault JF, Rehm J, Fischer B. The Cannabis Policy Framework by the Centre for Addiction and Mental Health: a proposal for a public health approach to cannabis policy in Canada. Int J Drug Policy 2016;34:1-4.

5. Volkow ND, Baler RD, Compton WM, et al. Adverse health effects of marijuana use. N Engl J Med 2014;370:2219-27.

6. The health effects of cannabis and cannabinoids: the current state of evidence and recommendations for research. Washington (DC): National Academies Press; 2017.
7. Lubman DI, Cheetham A. Yücel M. Cannabis and adolescent brain development. Pharmacol Ther 2015;148:1-16.

8. Ewing SWF, Sakhardande A, Blakemore S-J. The effect of alcohol consumption on the adolescent brain: a systematic review of MRI and fMRI studies of alcohol-using youth. Neuroimage Clin 2014;5:420-37.

9. Marshall EJ. Adolescent alcohol use: risks and consequences. Alcohol Alcohol 2014;49:160-4.

10. Mrazik M, Brooks BL, Jubinville A, et al. Psychosocial outcomes of sport concussions in youth hockey players. Arch Clin Neuropsychol 2016;31:297-304.

11. Forward KE, Seabrook JA, Lynch T, et al. A comparison of the epidemiology of ice hockey injuries between male and female youth in Canada. Paediatr Child Health 2014;19:418-22.

12. Canadian tobacco, alcohol and drugs survey (CTADS): 2015 summary. Ottawa: Health Canada; 2017.

13. Fischer B, Ala-Leppilampi K, Single E, et al. Cannabis law reform in Canada: Is the "saga of promise, hesitation and retreat" coming to an end? Can J Criminol Crim Justice 2003;45:265-98.

14. Bull SS, Brooks-Russell A, Davis JM, et al. Awareness, perception of risk and behaviors related to retail marijuana among a sample of Colorado youth. J Community Health 2017;42:278-86.
15. Lynskey MT, Hindocha C, Freeman TP. Legal regulated markets have the potential to reduce population levels of harm associated with cannabis use. Addiction 2016;111:2091-2.

16. Room R, Fischer B, Hall W, et al. Cannabis policy: moving beyond stalemate. New York: Oxford University Press; 2010.

17. Fischer B, Rehm J, Crepault JF. Realistically furthering the goals of public health by cannabis legalization with strict regulation: response to Kalant. Int J Drug Policy 2016;34:11-6.

18. Cotter A, Greenland J, Karam M. Drug-related offences in Canada, 2013. Ottawa: Statistics Canada; [modified 2015]. Cat no 85-002-x.

19. Haden M, Emerson B. A vision for cannabis regulation: a public health approach based on lessons learned from the regulation of alcohol and tobacco. Open Med 2014;8:e73-80.

20. Fischer B, Russell C, Sabioni P, et al. Lower-risk cannabis use guidelines (LRCUG): a comprehensive update of evidence and recommendations. Am J Public Health. In press.

21. Volkow ND, Swanson JM, Evins AE, et al. Effects of cannabis use on human behavior, including cognition, motivation, and psychosis: a review. JAMA Psychiatry 2016;73:292-7.

Competing interests: None declared. 